\title{
Effects of immune supplementation and immune challenge on bacterial assemblages in the avian cloaca
}

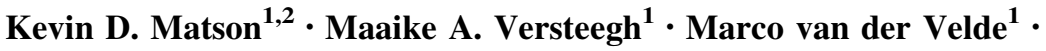 \\ B. Irene Tieleman ${ }^{1}$
}

Received: 9 July 2014/Revised: 4 February 2015/Accepted: 23 February 2015/Published online: 14 March 2015

(C) The Author(s) 2015. This article is published with open access at Springerlink.com

\begin{abstract}
Relationships between avian physiology and bacterial assemblages in the cloaca are poorly understood. We used molecular techniques to analyze cloacal swabs from pigeons that were subjected to two immunological manipulations: lysozyme supplementation and endotoxin challenge. From the swabs, we derived ecological indices of evenness, richness, and diversity of bacterial assemblages. Challenge led to changes in evenness that depended on supplementation. When analyzing these changes, we neutralized the effects of a possible statistical artifact by including the starting values as a covariate. Repeatability calculations suggested that swabbing reliably captured the evenness but not the richness or diversity of bacterial assemblages in the cloaca.
\end{abstract}

Keywords Microbial ecology - Denaturing gradient gel electrophoresis · Physiology · Columba livia · Cloacal swab

Communicated by K. C. Klasing.

Kevin D. Matson

kevin.matson@wur.nl

1 Animal Ecology Group, Centre for Ecological and Evolutionary Studies, University of Groningen, P.O. Box 11103, 9700 CC Groningen, The Netherlands

2 Resource Ecology Group, Department of Environmental Sciences, Wageningen University, P.O. Box 47, 6700 AA Wageningen, The Netherlands

\section{Zusammenfassung}

Auswirkungen von Immunsupplementierung und experimenteller Immunantwort auf die Bakterienzusammensetzung in der Kloake

Zusammenhänge zwischen der Physiologie von Vögeln und der Bakterienzusammensetzung in der Kloake sind weitgehend unbekannt. Wir haben molekulare Methoden verwendet, um Kloakenabstriche von Tauben zu untersuchen, die zwei verschiedenen Manipulationen des Immunsystems ausgesetzt waren: einer Unterstützung des Immunsystems durch Zugabe von Lysozymen und einer experimentell ausgelösten Immunreaktion. Von den Kloakenabstrichen haben wir ökologische Indices von Gleichverteilung, Artenzahl und Diversität der Bakterienzusammensetzung bestimmt. Eine Immunreaktion führte zu Veränderungen in der Gleichverteilung, die von der Unterstützung des Immunsystems mit Lysozymen abhängig war. Bei der statistischen Analyse der Veränderungen haben wir jeweils den entsprechenden Ausgangswert der Bakterienzusammensetzung als Kovariate verwendet, um einen potentiellen statistischen Artefakt auszuschließen. Berechnungen zur Reproduzierbarkeit der Ergebnisse deuten darauf hin, dass Abstriche die Gleichverteilung der Bakterienzusammensetzung verlässlich wiedergeben, nicht jedoch deren Artenzahl und Diversität.

\section{Introduction}

Ornithologists are increasingly interested in the physiological relationships between birds and the microbes that they harbor (Kohl 2012). To shed light on these 
relationships, investigators continue to develop, refine, and employ a variety of molecular genetic techniques, including denaturing gradient gel electrophoresis (DGGE), which can be useful alternatives to culture-based bacteriological techniques (van der Wielen et al. 2002; Grizard et al. 2014). In studies of domestic birds, such molecular analyses of gastrointestinal (GI) bacterial assemblages often utilize samples that are impractical or unethical to collect from wild birds, e.g., terminal samples (van der Wielen et al. 2002). Swabbing orifices, mucosa, and other surfaces of animals is a widely applicable and nonlethal alternative. Recent avian studies include data from swabs of cloacae (Klomp et al. 2008), choanae (Waite et al. 2012), and eggshells (Grizard et al. 2014). However, some swabbing procedures collect only subsets of the bacteria residing in swabbed areas (Grizard et al. 2014). The extent to which a bird's physiological state influences the samples collected via swabbing remains poorly studied.

The physiological state of a bird comprises elements that naturally change over timescales both short (e.g., acute phase responses) and long (e.g., seasonal or age-related patterns in reproduction). We investigated whether acute systemic changes in physiology translate into measurable changes in bacterial assemblages in the avian cloaca. To do so, we used DGGE to analyze cloacal swabs that were collected from pigeons before and during a study of the effects of immune supplementation and immune challenge (van de Crommenacker et al. 2010; Matson et al. 2012). While these manipulations clearly affect the physiology of pigeons (van de Crommenacker et al. 2010), the impacts of the same manipulations on the microbial ecology of the cloaca are unknown. Immune supplementation was achieved by oral administration of lysozyme, a non-specific antimicrobial enzyme that is produced endogenously by pigeons (Gavilanes et al. 1982; van de Crommenacker et al. 2010). Immune challenge took the form of an injection with lipopolysaccharide (LPS), a bacterial endotoxin that triggers energetically expensive febrile responses in pigeons (Nomoto 1996; van de Crommenacker et al. 2010) and affects bacterial assemblages at the murine cecum (Sze et al. 2014). We used ecological indices of evenness, richness, and diversity (Hill 1973; Hooper et al. 2005) to compare the LPS-induced changes in bacterial assemblages between the lysozyme-supplemented and control groups (van de Crommenacker et al. 2010).

\section{Materials and methods}

\section{Study subjects and setup}

We studied 16 homing pigeons (Columba livia; University of Groningen Animal Experimentation Committee license no. 5095). Since van de Crommenacker et al. (2010) have comprehensively described the study subjects and setup employed, we provide only key information here.

The flock was divided into lysozyme-treatment and control groups (four $\odot$, four $\hat{o}$ per group). Treatment and control birds underwent similar seven-day experimental routines. On each of the first 6 days, we orally dosed each bird either with $180 \mathrm{mg}$ of lysozyme (from chicken egg white; L6876; Sigma, St. Louis, MO, USA) in $1 \mathrm{~mL}$ phosphate-buffered saline (PBS, P4417; Sigma) or with $1 \mathrm{~mL}$ of PBS only. On days four and six, birds were removed from their aviary for metabolic measurements, which meant they were isolated and fasted for $22 \mathrm{~h}$. The protocols on days four/five and six/seven were identical with one exception. On day six, $4 \mathrm{~h}$ into the 22-h fast, all birds received an endotoxin challenge: an intraperitoneal injection of $2 \mathrm{~mL} \mathrm{~kg}^{-1}$ body mass of a $1.25 \mathrm{mg} \mathrm{mL} \mathrm{m}^{-1}$ solution of LPS (from Salmonella enterica serotype typhimurium; L7261; Sigma) dissolved in PBS. Upon removing each bird from its metabolic chamber on the mornings of day five (i.e., $30 \mathrm{~h}$ pre-challenge) and day seven (i.e., $18 \mathrm{~h}$ post-challenge), we collected the swabs that are the focus of the current report. At the $18 \mathrm{~h}$ postchallenge time point, multiple biomarkers (e.g., haptoglobin concentration, metabolic rate, etc.) indicate acute phase responses in pigeons (van de Crommenacker et al. 2010). We also collected swabs ca. 4 months before the experiment as part of a monitoring program. We used these samples to check whether groups differed by chance before the experimental treatments.

\section{Cloacal swab collection}

We sampled birds by fully inserting the rayon tip of a sterile swab (112598; LP Italiana, Milan, Italy) into the cloaca and rotating the plastic shaft back and forth for about $10 \mathrm{~s}$. Immediately upon removal from the cloaca, the rayon tip and a small section of adjoining shaft (below the point that was handled) were snapped off into a sterile 1.5$\mathrm{mL}$ tube. Samples were stored at $-20{ }^{\circ} \mathrm{C}$ until further processing.

\section{DNA extraction, PCR, and DGGE}

We extracted DNA from 48 cloacal swabs using the FastDNA SPIN Kit for Soil (116560200; MP Biomedicals, Santa Ana, CA, USA) following the manufacturer's protocol.

We used PCR to amplify bacterial $16 \mathrm{~S}$ rRNA genes in $25-\mu l$ reactions that contained $0.2 \mathrm{mM}$ of each dNTP, $1 \mu \mathrm{l}$ $10 \times \mathrm{NH}_{4}$ buffer (BIO-37025; Bioline, London, UK), $1.75 \mathrm{mM} \mathrm{MgCl}_{2}, 0.25 \mu \mathrm{l}$ formamide, $0.03 \mu \mathrm{l}$ bovine serum albumin (10711454001; Roche Diagnostics, IN, USA), 
$0.2 \mu \mathrm{M}$ primer F968-GC (including a 40-mer GC clamp at the $5^{\prime}$ side; (Brons and van Elsas 2008), 0.2 $\mu \mathrm{M}$ primer R1401.1b (Brons and van Elsas 2008), 1.25 U of Biotaq DNA polymerase (BIO-21040; Bioline), and approximately $5 \mathrm{ng}$ template DNA. Our PCR program had four stages: initial denaturation for $5 \mathrm{~min}$ at $94{ }^{\circ} \mathrm{C}$; ten touchdown cycles of $1 \mathrm{~min}$ at $94{ }^{\circ} \mathrm{C}, 1 \mathrm{~min}$ at $60{ }^{\circ} \mathrm{C}$ (annealing), and $2 \mathrm{~min}$ at $72{ }^{\circ} \mathrm{C}$ with a $0.5^{\circ} \mathrm{C}$ decrease in the annealing temperature per cycle; 25 cycles of $1 \mathrm{~min}$ at $94{ }^{\circ} \mathrm{C}, 1 \mathrm{~min}$ at $55^{\circ} \mathrm{C}$, and $2 \mathrm{~min}$ at $72^{\circ} \mathrm{C}$; final extension for $10 \mathrm{~min}$ at $72{ }^{\circ} \mathrm{C}$. We used agarose gel $(1 \%)$ electrophoresis and ethidium bromide staining to assess the PCR products.

We used an INGENYphorU system (Ingeny, Goes, Netherlands) for DGGE. We followed the protocols of Brons and van Elsas (2008), except that we used a denaturant gradient range of $45-65 \%$ in our two gels. We scored the DGGE banding patterns using images imported into GelCompar II (Applied Maths, Sint-Martens-Latem, Belgium). One sample ( $\hat{\jmath}$, lysozyme, post-challenge) failed to produce a visible PCR product or any DGGE bands. This individual was excluded from all analyses due to the repeated measures design.

\section{Bacterial assemblage variables and statistical analyses}

We normalized the intensities of all bands within each sample (i.e., values summed to one). Based on the number and the normalized intensities of the bands in each sample, we derived variables to describe the bacterial assemblages using Canoco (version 4.55). We focused on the four variables originally annotated by Hill (1973): total number of bands present, also known as richness $\left(N_{0}\right)$; exponent (Shannon's index), also known as effective diversity of Shannon's index $\left(N_{1}\right) ; 1 /($ Simpson's index $)$, also known as effective diversity of the Simpson's index $\left(N_{2}\right)$; and evenness $\left(N_{2} / N_{1}\right)$.

We used linear models ("lm" in $\mathrm{R}$ version 2.15.0) followed by ANOVA ("Anova" with type $=2$ in R package "car"). Initially all linear models of within-individual LPSinduced changes $\left(\Delta_{\text {LPS }}\right)$ in bacterial assemblage variables included sex and group (lysozyme-treated or control) and the interaction between sex and group. These linear models also included the pre-LPS-challenge values of the dependent variable under consideration as a covariate. With $P>0.4$, both sex and the interaction between sex and group were always removed. Final linear models included only group and the covariate. Using linear mixed effects models ("lme" in R package "nlme") with LPS challenge status (pre or post) as a fixed effect and individual identity as a random effect, we calculated the repeatability of the bacterial assemblage variables using the control (non- lysozyme-treated) birds (Lessells and Boag 1987). With the effect of LPS challenge accounted for, a high repeatability would indicate that the corresponding bacterial assemblage variable reflects a characteristic trait of individuals regardless of challenge status.

As an aside, we wish to note a post hoc exploratory analysis in which we employed nonmetric multidimensional scaling (NMDS) to investigate experimental effects on the structure of bacterial assemblages in the cloaca (in contrast to Hill's summary variables). NMDS failed to reveal any visually compelling grouping of assemblage structure based on lysozyme treatment or LPS challenge.

\section{Results}

Around 4 months before initiating the experiment, the control and lysozyme-treated groups did not differ in any of the bacterial assemblage variables $\left(F_{1,12}<1.1\right.$, $P>0.3$ ). Following van de Crommenacker et al. (2010), we calculated descriptive statistics for the four groups in the experiment (Table 1). The experiment revealed that LPS-induced changes in evenness differed between the lysozyme-treated and control groups (Table 2). Moreover, LPS-induced changes in evenness and in effective diversity of the Simpson's index correlated negatively with prechallenge values (Table 2; Fig. 1). Additionally, we conducted auxiliary analyses on four data subsets: we investigated the effects of LPS in the control group and in the lysozyme-treated group (Table 3), and we investigated the effects of lysozyme at the pre-challenge time point and at the post-challenge time point (Table 3 ). These auxiliary analyses reiterated the importance of the combined treatments (i.e., effects of lysozyme at the post-challenge time point). Evenness exhibited the highest repeatability, $R=0.60 \pm 0.23$ (standard error; $P=0.06$ ), meaning that this variable might be a characteristic feature of individuals. The same cannot be said of the other variables, which had exceedingly low repeatabilities $(R<0.01)$.

\section{Discussion}

In ecology, evenness and richness contribute to diversity (Hooper et al. 2005). We showed that LPS-induced changes in the evenness (but not richness or diversity) of bacterial assemblages in the cloaca of pigeons differed between the lysozyme-treated and control groups. LPS challenge led to a larger decrease in evenness in the lysozyme-supplemented group than in the control group. Evenness relates to myriad ecosystem properties (Hooper et al. 2005), including stability, as illustrated by a study showing that high initial evenness makes microbial 
Table 1 Means and standard errors for bacterial assemblage variables in the cloaca of both control and lysozyme-treated pigeons, both before and after LPS challenge

\begin{tabular}{lllllll}
\hline Variable & \multicolumn{2}{l}{ Pre-challenge } & & \multicolumn{2}{l}{ Post-challenge } \\
& & Lysozyme-treated group & Control group & & Lysozyme-treated group & Control group \\
\hline$N_{0}$ & No. of DGGE bands present & $13.86 \pm 1.75$ & $12.63 \pm 0.82$ & & $12.71 \pm 1.96$ & $15.13 \pm 1.39$ \\
$N_{1}$ & Exponent (Shannon's index) & $10.78 \pm 1.48$ & $10.41 \pm 0.80$ & $9.43 \pm 1.42$ & $12.20 \pm 1.18$ \\
$N_{2}$ & $1 /$ (Simpson's index) & $9.03 \pm 1.40$ & $9.03 \pm 0.88$ & & $7.48 \pm 1.10$ & $10.46 \pm 1.05$ \\
$N_{2} / N_{1}$ & Evenness & $0.824 \pm 0.023$ & $0.860 \pm 0.023$ & & $0.800 \pm 0.015$ & $0.857 \pm 0.015$ \\
\hline
\end{tabular}

Table 2 Estimates (i.e., $\beta$ values) and statistics of the effects of the lysozyme treatment and the pre-challenge value covariate on the change in cloacal bacterial assemblage variables from the pre- to the post-challenge time point (i.e., $\Delta$ LPS)

\begin{tabular}{|c|c|c|c|c|c|c|c|}
\hline \multicolumn{2}{|c|}{ Variable $\left(\Delta_{\text {LPS }}\right)$} & \multicolumn{3}{|l|}{ Lysozyme } & \multicolumn{3}{|c|}{ Covariate: pre-challenge value } \\
\hline & & Estimate $\pm \mathrm{SE}$ & $F_{1,12}$ & $P$ & Estimate $\pm \mathrm{SE}$ & $F_{1,12}$ & $P$ \\
\hline$N_{0}$ & No. of DGGE bands present & $-2.99 \pm 2.32$ & 1.65 & 0.22 & $-0.53 \pm 0.34$ & 2.42 & 0.15 \\
\hline$N_{1}$ & Exponent (Shannon's index) & $-2.93 \pm 1.77$ & 2.73 & 0.12 & $-0.58 \pm 0.30$ & 3.68 & 0.08 \\
\hline $\mathrm{N}_{2}$ & 1/(Simpson's index) & $-2.98 \pm 1.47$ & 4.11 & 0.07 & $-0.64 \pm 0.25$ & 6.39 & 0.03 \\
\hline$N_{2} / N_{1}$ & Evenness & $-0.051 \pm 0.022$ & 5.20 & 0.04 & $-0.835 \pm 0.178$ & 21.91 & $<0.001$ \\
\hline
\end{tabular}

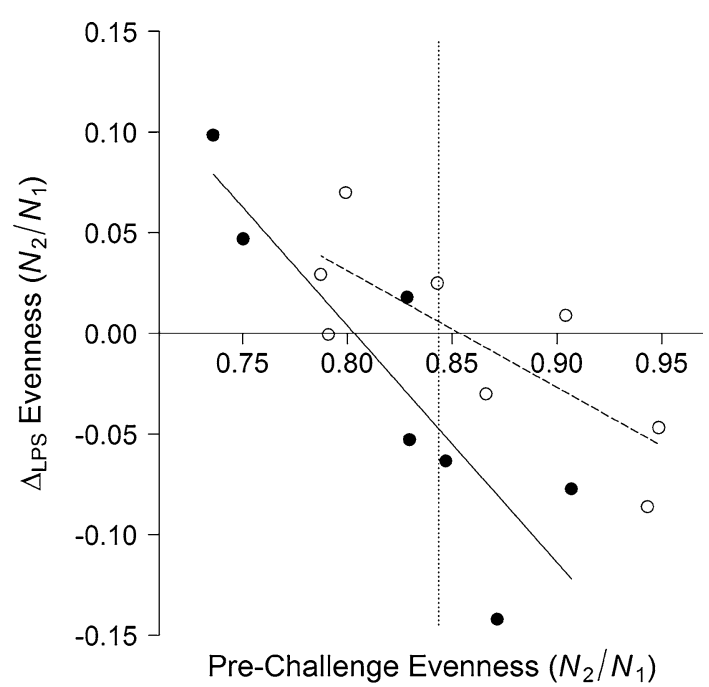

Fig. 1 Relationship between evenness in bacterial assemblages in the cloaca before the LPS challenge and the change in evenness due to the LPS challenge (i.e., $\Delta_{\mathrm{LPS}} ; F_{1,12}<21.9, P<0.001$ ) for both control (open circles, dashed line: $y=-0.58 x+0.50, R^{2}=0.61$ ) and lysozyme-treated (filled circles, solid line: $y=-1.18 x+0.95$, $R^{2}=0.77$ ) pigeons. The difference between the two regression lines suggests that lysozyme treatment affects how LPS challenge influences evenness $\left(F_{1,12}<5.2, P=0.04\right)$. The data also suggest a statistical artifact known as regression to the mean. Specifically, individuals with low initial evenness generally increased after LPS challenge (6/8 below-average individuals showed increases), while individuals with high initial evenness generally decreased (6/7 aboveaverage individuals showed decreases). The vertical line indicates the overall mean evenness $(0.844)$ communities more resistant to environmental stress (Wittebolle et al. 2009). Our result hints at a similar relationship: the lysozyme-treated group, with its lower mean evenness, exhibited a further reduction in evenness after LPS challenge.

Lysozyme supplementation, LPS injection, and their interaction affect avian physiological function, including metabolism and inflammation (van de Crommenacker et al. 2010). However, the same manipulations in the same birds were generally less effective at eliciting differences in bacterial assemblages in the cloaca. One possible reason is that the experimental manipulations did not differentially impact the cloacal microenvironment. For example, LPS-induced increases in cloacal temperature are small $\left(<1{ }^{\circ} \mathrm{C}\right)$ and do not differ between lysozyme-treated and control groups (van de Crommenacker et al. 2010). Furthermore, the 22-h fast which preceded the collection of swabs and covered the entire LPS challenge experimental timeline eliminated the possibility of LPS-induced differences in food consumption, and thereby likely lessened other related differences [e.g., in defecation, since mean digesta retention times are $<9 \mathrm{~h}$ in pigeons (Hatt 2002)]. Similar digestive states might have led to relatively homogeneous cloacal microenvironments.

At the individual level, challenge-induced changes in evenness correlated inversely with pre-challenge values of evenness. This correlation suggests a biologically germane relationship linking initial evenness and resistance to change (Wittebolle et al. 2009). However, caution is warranted since 
Table 3 Estimates (i.e., $\beta$ values) and statistics of the effects of (A) LPS in the lysozyme-treated and control groups and (B) lysozyme at the pre- and post-challenge time points

\begin{tabular}{|c|c|c|c|c|c|c|c|}
\hline \multicolumn{8}{|l|}{ (A) } \\
\hline \multicolumn{2}{|c|}{ Variable } & \multicolumn{3}{|c|}{ LPS in lysozyme-treated group } & \multicolumn{3}{|c|}{ LPS in control group } \\
\hline & & Estimate $\pm \mathrm{SE}$ & $F_{1,6}$ & $P$ & Estimate $\pm \mathrm{SE}$ & $F_{1,7}$ & $P$ \\
\hline$N_{0}$ & No. of DGGE bands present & $-1.14 \pm 1.34$ & 0.73 & 0.42 & $2.50 \pm 1.62$ & 2.39 & 0.17 \\
\hline$N_{1}$ & Exponent (Shannon's index) & $-1.35 \pm 1.02$ & 1.76 & 0.23 & $1.79 \pm 1.43$ & 1.58 & 0.25 \\
\hline $\mathrm{N}_{2}$ & 1/(Simpson's index) & $-1.55 \pm 0.90$ & 2.93 & 0.14 & $1.43 \pm 1.38$ & 1.08 & 0.33 \\
\hline$N_{2} / N_{1}$ & Evenness & $-0.025 \pm 0.028$ & 0.78 & 0.41 & $-0.004 \pm 0.017$ & 0.05 & 0.83 \\
\hline \multicolumn{8}{|l|}{ (B) } \\
\hline \multirow{2}{*}{\multicolumn{2}{|c|}{ Variable }} & \multicolumn{3}{|c|}{ Lysozyme at pre-challenge } & \multicolumn{3}{|c|}{ Lysozyme at post-challenge $^{a}$} \\
\hline & & Estimate $\pm \mathrm{SE}$ & $F_{1,12}$ & $P$ & Estimate $\pm \mathrm{SE}$ & $F_{1,12}$ & $P$ \\
\hline$N_{0}$ & No. of DGGE bands present & $1.23 \pm 1.85$ & 0.44 & 0.52 & $-2.99 \pm 2.32$ & 1.65 & 0.22 \\
\hline$N_{1}$ & Exponent (Shannon's index) & $0.37 \pm 1.62$ & 0.05 & 0.82 & $-2.93 \pm 1.77$ & 2.73 & 0.12 \\
\hline$N_{2}$ & 1/(Simpson’s index) & $0.00 \pm 1.61$ & 0.00 & 1.00 & $-2.98 \pm 1.47$ & 4.11 & 0.07 \\
\hline$N_{2} / N_{1}$ & Evenness & $-0.036 \pm 0.033$ & 1.18 & 0.30 & $-0.051 \pm 0.022$ & 5.20 & 0.04 \\
\hline
\end{tabular}

${ }^{\text {a }}$ Pre-challenge measurement included as covariate individuals with low initial evenness generally increased after LPS challenge (6/8 below-average individuals showed increases) and individuals with high initial evenness generally decreased (6/7 above-average individuals showed decreases). Consequently, these results suggest a statistical artifact, regression to the mean (RTM), which "can make natural [random] variation in repeated data look like real change" (Barnett et al. 2005). RTM occurs when measurements further from the mean are followed by measurements closer to the mean. It should be stressed that the identification of RTM at our data analysis stage does not negate the difference between the lysozyme-treated and control groups in the current study. That said, using mean values calculated from two or more baseline swabs could help eliminate RTM in future studies (Barnett et al. 2005).

Measurement error can contribute to RTM, yet the high repeatability of evenness suggests that our swab technique is capable of reliably capturing this facet of bacterial assemblages in the cloaca. However, the extremely low repeatabilities of richness and diversity raise concerns about the technique and could help explain the lack of experimental effects. The need to investigate the repeatability of bird-associated bacterial assemblages has been identified previously (Klomp et al. 2008). Such investigations should consider methodological factors (i.e., measurement error) and biological ones, such as transit within birds or transmission between birds (Klomp et al. 2008). Nevertheless, our study sets the stage for future studies of repeatability and more generally suggests that acute and systemic changes in avian physiology can interact to influence bacterial assemblages in the cloaca.

Acknowledgments S. Grizard, J.K. Brons, M.C.P. Silva and the Microbial Ecology Group facilitated the DGGE. Anonymous reviewers helped improve the manuscript, and A. Hegemann helped by translating our abstract into German. The Netherlands Organisation for Scientific Research funded K.D.M. (Veni 863.08.026) and B.I.T (Vidi 864.10.012).

Open Access This article is distributed under the terms of the Creative Commons Attribution License which permits any use, distribution, and reproduction in any medium, provided the original author(s) and the source are credited.

\section{References}

Barnett AG, van der Pols JC, Dobson AJ (2005) Regression to the mean: what it is and how to deal with it. Int $\mathrm{J}$ Epidemiol 34:215-220. doi:10.1093/ije/dyh299

Brons JK, van Elsas JD (2008) Analysis of bacterial communities in soil by use of denaturing gradient gel electrophoresis and clone libraries, as influenced by different reverse primers. Appl Environ Microbiol 74:2717-2727. doi:10.1128/AEM.02195-07

Gavilanes JG, De Buitrago GG, Del Pozo AM et al (1982) Pigeon egg white lysozyme. Int J Pept Protein Res 20:238-245. doi:10.1111/ j.1399-3011.1982.tb03053.x

Grizard S, Dini-Andreote F, Tieleman BI, Salles JF (2014) Dynamics of bacterial and fungal communities associated with eggshells during incubation. Ecol Evol 4:1140-1157. doi:10.1002/ece3.1011

Hatt J-M (2002) Digesta kinetics in feral pigeons (Columba livia). In: Proc Joint Nutrition Symp, Antwerp, Belgium, 21-25 Aug 2002, p 86

Hill MO (1973) Diversity and evenness: a unifying notation and its consequences. Ecology 54:427-432. doi:10.2307/1934352

Hooper DU, Chapin FS, Ewel JJ et al (2005) Effects of biodiversity on ecosystem functioning: a consensus of current knowledge. Ecol Monogr 75:3-35. doi:10.1890/04-0922

Klomp JE, Murphy MT, Smith SB et al (2008) Cloacal microbial communities of female spotted towhees Pipilo maculatus: microgeographic variation and individual sources of variability. J Avian Biol 39:530-538. doi:10.1111/j.0908-8857.2008.04333.x

Kohl K (2012) Diversity and function of the avian gut microbiota. J Comp Physiol B 182:591-602. doi:10.1007/s00360-012$0645-\mathrm{z}$ 
Lessells CM, Boag PT (1987) Unrepeatable repeatabilities: a common mistake. Auk 104:116-121

Matson KD, Horrocks NPC, Versteegh MA, Tieleman BI (2012) Baseline haptoglobin concentrations are repeatable and predictive of certain aspects of a subsequent experimentally induced inflammatory response. Comp Biochem Physiol A Mol Integr Physiol 162:7-15. doi:10.1016/j.cbpa.2012.01.010

Nomoto S (1996) Diurnal variations in fever induced by intravenous LPS injection in pigeons. Pflügers Arch 431:987-989

Sze MA, Tsuruta M, Yang S-WJ et al (2014) Changes in the bacterial microbiota in gut, blood, and lungs following acute LPS instillation into mice lungs. PLoS One 9:e111228. doi:10.1371/ journal.pone. 0111228

Van de Crommenacker J, Horrocks NPC, Versteegh MA et al (2010) Effects of immune supplementation and immune challenge on oxidative status and physiology in a model bird: implications for ecologists. J Exp Biol 213:3527-3535. doi:10.1242/jeb.045591

Van der Wielen PWJJ, Keuzenkamp DA, Lipman LJA et al (2002) Spatial and temporal variation of the intestinal bacterial community in commercially raised broiler chickens during growth. Microb Ecol 44:286-293. doi:10.1007/s00248-002-2015-y

Waite DW, Deines P, Taylor MW (2012) Gut microbiome of the critically endangered New Zealand parrot, the kakapo (Strigops habroptilus). PLoS One 7:e35803. doi:10.1371/journal.pone. 0035803

Wittebolle L, Marzorati M, Clement L et al (2009) Initial community evenness favours functionality under selective stress. Nature 458:623-626. doi:10.1038/nature07840 